\title{
Sinopse do gênero Phyllanthus L. (Phyllanthaceae) do Estado de São Paulo
}

\author{
Erika Ramos Martins ${ }^{1,3}$ e Letícia Ribes de Lima ${ }^{2}$
}

Recebido: 30.04.2010; aceito: 17.03.2011

\begin{abstract}
Synopsis of the genus Phyllanthus L. (Phyllanthaceae) of São Paulo state). The genus Phyllanthus occurs worldwide, and in Brazil the latest survey points the occurrence of 107 species. The survey also shows that approximately one quarter of them are mostly found in rocky fields, cerrados and caatingas. The purpose of this study is to summarize the genus Phyllanthus in order to contribute to the completion of the monograph of the family Phyllanthaceae as a whole. Furthermore, this study was aimed to better circurscribe the species that occur in São Paulo State as well as present information morphology, geographical distribution and taxonomy about the taxa studied. In the State of Sao Paulo 16 species of the genus were found.
\end{abstract}

Key words: Euphorbiaceae s.l., floristic, geographical distribution, taxonomy

RESUMO - (Sinopse do gênero Phyllanthus L. (Phyllanthaceae) do Estado de São Paulo). O gênero Phyllanthus ocorre em todas as regiões do planeta e no Brasil, o levantamento mais recente aponta a ocorrência de 107 espécies, das quais cerca de um quarto são encontradas, principalmente, nos campos rupestres, cerrados e caatingas. O objetivo do presente trabalho foi elaborar a monografia do gênero Phyllanthus do Estado de São Paulo, contribuindo assim para o término da monografia da família Phyllanthaceae para o Projeto "Flora Fanerogâmica do Estado de São Paulo". Além disso, esse trabalho visou buscar um melhor conhecimento e circunscrição das espécies que ocorrem no estado, bem como apresentar informações sobre morfologia, distribuição geográfica e taxonomia sobre os táxons estudados. No Estado de São Paulo foram encontradas 16 espécies do gênero.

Palavras-chave: distribuição geográfica, Euphorbiaceae s.l., florística, taxonomia

\section{Introdução}

Com o advento da sistemática filogenética houve uma grande mudança na circunscrição das Euphorbiaceae s.l., pois as evidências trazidas pelos dados moleculares de alguns marcadores, como $18 \mathrm{~S}$ rDNA, $r b c L$ e $a t p B$, não suportavam a família como um grupo monofilético (Chase et al. 1993). Deste modo, em 2003, o APG propôs que as Euphorbiaceae s.l. fossem divididas em três famílias distintas: as Euphorbiaceae s.s., compreendendo apenas os grupos uniovulados Euphorbioideae, Crotonoideae e Acalyphoideae; Picrodendraceae, constituída pelo grupo biovulado Oldfieldioideae e, finalmente, Phyllanthaceae, constituída pelo grupo biovulado Phyllanthoideae. As três famílias possuem frutos e embriologia similares, entretanto algumas características foliares, florais, polínicas e da anatomia da testa da semente são diferentes.

Mais recentemente, Hoffmann et al. (2006), baseados tanto em dados moleculares, quanto morfológicos, propuseram que as Euphorbiaceae s.l. fossem divididas em cinco famílias, as três famílias citadas anteriormente, ou seja, Euphorbiaceae s.s., Phyllanthaceae e Picrodendraceae, além de Pandaceae e Putranjivaceae, ambas dotadas de lóculos do ovário biovulados.

Phyllanthaceae pode ser distinguida de Euphorbiaceae s.s. por apresentar os lóculos do ovário biovulados (vs. lóculos uniovulados), pela ausência de canais laticíferos e, consequentemente, de látex branco ou colorido, caráter relativamente comum nas

1. Estagiária de Iniciação Científica, Instituto de Botânica, Av. Miguel Stéfano 3031, 04301-012 São Paulo, SP, Brasil

2. Universidade Federal de São Carlos, Centro de Ciências Agrárias, Rodovia Anhanguera, km 174, SP 330, 13600-970 Araras, SP, Brasil

3. Autora para correspondência: eramosmartins@ hotmail.com 
Euphorbiaceae s.s., além da ausência de arilo nas sementes, característica também presente na maioria das Euphorbiaceae s.s. Pode também ser separada da pequena família Picrodendraceae, que também apresenta os lóculos do ovário biovulados, pela presença de um disco nectarífero nas flores masculinas e femininas, pela frequente presença de estiletes bífidos e pela ausência do pólen espinhoso (característico de Picrodendraceae). As Picrodendraceae ocorrem, principalmente, no Hemisfério Sul e têm como principais representantes os gêneros Austrobuxus, Oldfieldia, Pseudanthus, Tetracoccus e Picrodendron.

De acordo com Judd et al. (2009), Phyllanthaceae é presumivelmente monofilética com base nas flores unissexuais, nos estiletes bífidos e nos frutos esquizocárpicos. Segundo Kathriarachchi et al. (2006), alguns estudos filogenético (e.g. Wurdack et al. 2004, Kathriarachchi et al. 2005, Samuel et al. 2005) apoiam o monofiletismo da família Phyllanthaceae, que é dividida em dois clados principais: a) o primeiro deles onde estão inseridos os gêneros Phyllanthus, Savia, Cleistanthus e Andrachne, além de outros pequenos táxons afins, que se caracteriza pela presença de plantas, em geral, monóicas, com inflorescências fasciculadas, ausência de células epidérmicas taníferas e com frutos, geralmente, de deiscência explosiva; b) o segundo, onde se encontram Antidesma, Bischofia e Hieronyma, entre outros gêneros menores, possui representantes, em geral, dióicos, com inflorescências racemosas, presença de células epidérmicas taníferas e frutos tardia ou incompletamente deiscentes, ou mesmo indeiscentes.

Assim como as Euphorbiaceae s.s., as Phyllanthaceae também apresentam flores unissexuais, estiletes bífidos e frutos esquizocárpicos, porém a filogenia mostra que essas características parecem ter evoluído de maneira independente nas diferentes linhagens do que eram as Euphorbiaceae s.l.

\section{Material e métodos}

Área de estudo - O Estado de São Paulo localiza-se entre as latitudes $19^{\circ} 47^{\prime}$ e $25^{\circ} 19^{\prime} \mathrm{S}$ e as longitudes $53^{\circ} 06^{\prime}$ e $44^{\circ} 10^{\prime} \mathrm{W}$ e tem uma área total de $248.256 \mathrm{~km}^{2}$, sendo cortado pelo Trópico de Capricórnio (Wanderley et al. 2005). Varia em altitude desde o nível do mar até $2.770 \mathrm{~m}$ no seu ponto mais alto, a Pedra da Mina, na Serra da Mantiqueira (Wanderley et al. 2005). O clima é caracterizado por estações úmidas e secas bem definidas, na maior parte do estado, exceto nas encostas da Serra do Mar, próximo à costa, onde a estação seca é muito curta e, embora o clima seja basicamente tropical, geadas esporádicas podem ocorrer durante o inverno (junhoagosto) em regiões de baixa altitude do centro-oeste $\mathrm{e}$, regularmente, nas montanhas acima de $1.200 \mathrm{~m}$ de altitude (Wanderley et al. 2005).

Análise das espécies de Phyllanthus do Estado de São Paulo - Foi realizado o levantamento bibliográfico das principais publicações referentes ao gênero Phyllanthus, tanto dos trabalhos de flora envolvendo o gênero, quanto das descrições originais das espécies encontradas no Estado de São Paulo. Deste modo, trabalhos referentes à taxonomia do gênero, bem como trabalhos de levantamentos florísticos, distribuição geográfica, entre outros, foram utilizados para auxiliar na identificação dos táxons, na elaboração dos comentários e na compilação das informações sobre a distribuição geográfica das espécies. Além das fontes bibliográficas, as informações contidas nas etiquetas das exsicatas também foram utilizadas.

Foram analisadas coleções do gênero Phyllanthus depositadas nos principais herbários do Estado de São Paulo, entre eles os herbários do Instituto de Botânica (SP), da Universidade de São Paulo (SPF), da Universidade Estadual de Campinas (UEC), da Escola Superior de Agricultura "Luiz de Queiroz" da Universidade de São Paulo (ESA), do Instituto Florestal (SPSF), da Prefeitura do Município de São Paulo Herbário Municipal (PMSP) e da Universidade Estadual Paulista Júlio de Mesquita Filho (HRCB) (acrônimos de acordo com Holmgren et al. 1990), a fim de abranger toda variabilidade morfológica dos táxons ocorrentes no Estado de São Paulo.

A identificação do material analisado foi realizada tanto pelo uso de chaves analíticas de identificação, quanto por comparação dos resultados obtidos com dados da bibliografia referentes ao grupo estudado, bem como por comparação com as coleções já identificadas por especialistas no gênero. Todos os caracteres vegetativos e reprodutivos das espécies de Phyllanthus foram analisados em detalhe, sob estereomicroscópio.

As ilustrações foram elaboradas por desenhista especializado, que utilizou fotografias e exsicatas para desenhar os hábitos de algumas das espécies. Para ilustrar características das flores, dos frutos e das sementes esses órgãos foram rehidratados e observados sob estereomicroscópio com câmara clara acoplada. 


\section{Resultados e Discussão}

No Estado de São Paulo foram encontradas 16 espécies do gênero Phyllanthus: P. acuminatus Vahl, $P$. acutifolius Poir. ex Spreng., P. avicularis Müll.Arg., P. caroliniensis Walter, P. cladotrichus Müll.Arg., P. claussenii Müll.Arg., P. glaziovii Müll.Arg., P. juglandifolius Willd., P. niruri L., P. orbiculatus Rich., P. regnellianus Müll.Arg., $P$. riedelianus Müll.Arg., P. stipulatus (Raf.) G.L.Webster, P. tenellus Roxb., P. umbratus Müll.Arg. e P. urinaria L.

A publicação da "Lista de Espécies da Flora do Brasil" apresentou 3 subespécies de Phyllanthus para o Estado de São Paulo, o que enriqueceu o conhecimento do gênero. As subespécies apresentadas na lista que ocorrem em São Paulo são: P. caroliniensis subsp. guianensis (Klotzsch) G.L.Webster, P. juglandifolius Willd. subsp juglandifolius e P. urinaria L. subsp. urinaria. Além dessas subespécies, foi apresentada também uma variedade de P. tenellus - P. tenellus var. tenellus, para o Estado de São Paulo. Entretanto, estas subespécies e variedade não foram incluídas neste levantamento porque preferimos não trabalhar com táxons infraespecíficos. Outras cinco espécies (Phyllanthus amarus Schumach., P. lindbergii Müll.Arg., P. minutulus Müll.Arg., P. rosellus (Müll.Arg.) Müll.Arg. e P. subemarginatus Müll.Arg.) foram apresentadas na "Lista de Espécies da Flora do Brasil" como ocorrentes no Estado de São Paulo, continuam não incluídas no trabalho, pois mesmo analisando criteriosamente todas as coleções depositadas nos principais herbários de São Paulo, não foi encontrado nenhum material dessas espécies. Também foi consultado o Prof. Ricardo Secco, do
Museu Botânico Emílio Goeldi (Herbário MG), sobre materiais desses táxons coletados no Estado de São Paulo e a resposta também foi negativa. Nenhum dos materiais-testemunho citados na "Lista de Espécies da Flora do Brasil", dessas cinco espécies, é proveniente do Estado de São Paulo.

Phyllanthus L., Sp. Pl. 2: 981. 1753

Ervas, arbustos ou árvores, 0,1-8 m alt.; monóicos ou, mais raramente, dióicos; padrão de ramificação não filantóide, com ramos persistentes variadamente ramificados, ou filantóide com ramos, em geral decíduos e dispostos espiraladamente ao longo do caule, ramos cilíndricos, às vezes achatados na porção terminal, com ou sem indumento. Folhas simples, inteiras, alternas, pecioladas, estipulas presentes às vezes apenas nas plantas jovens; pecíolos sempre menores que as lâminas; lâminas membranáceas, cartáceas ou coriáceas elípticas, circulares, oblongas, obovais, ovais, faces adaxial e abaxial glabras ou indumentadas; nervação broquidódroma, cladódroma ou eucamptódroma. Inflorescências axilares, usualmente cimosas, címulas unissexuais ou bissexuais ou, às vezes, flores solitárias. Flores masculinas monoclamídeas, gamossépalas, pediceladas, sépalas 5 ou 6; estames (2-)3-6 livres ou unidos; anteras livres ou unidas, rimosas, rimas horizontais ou verticais; disco inteiro a 6-lobado; grãos de pólen prolatos a esféricos, colporados a porados. Flores femininas monoclamídeas, gamossépalas, pediceladas, sépalas 5 ou 6; gineceu 3-locular; óvulos 2 por lóculo; estiletes 3, livres ou unidos na base, geralmente divididos. Cápsula septicida, raramente baga ou drupa. Sementes 2 por lóculo, trígonas, lisas ou verruculosas, com ou sem indumento.

Chave para as espécies de Phyllanthus do Estado de São Paulo

1. Flores masculinas com seis sépalas

2. Árvores ou arvoretas, 2 a 8 metros de altura

3. Folhas subcartáceas com face adaxial glabra 12. P. riedelianus

3. Folhas membranáceas com tricomas simples na face adaxial

4. Planta com ramos cobertos por tricomas simples; folhas com margem não revoluta e nervação broquidódroma 1. P. acuminatus

4. Planta com ramos glabros; folhas com margem revoluta e nervação cladódroma

15. P. umbratus

2. Ervas a subarbustos, 0,1 a 1 metro de altura

5. Flores masculinas com 3 estames totalmente unidos 16. P. urinaria

5. Flores masculinas com 3 estames livres 
6. Folhas largamente elípticas, largamente ovais a circulares; pedicelo das flores femininas sempre maiores que $1,5 \mathrm{~mm}$ de comprimento .... 10. P. orbiculatus

6. Folhas elípticas a obovais; pedicelo das flores femininas com até $1,0 \mathrm{~mm}$ de comprimento

7. Folhas com face adaxial glabra e margem levemente revoluta ....................... 3. P. avicularis

7. Folhas com face adaxial glabrescente a esparsamente pubescente, tricomas simples e margem não revoluta

4. P. caroliniensis

1. Flores masculinas com cinco sépalas

8. Folhas cartáceas ou coriáceas

9. Flores masculinas com 3 estames livres

7. P. glaziovii

9. Flores masculinas com 4 a 6 estames completamente unidos ou unidos aos pares

10. Faces adaxial e abaxial das folhas glabras; pedicelo das flores masculinas 0,4 a $0,6 \mathrm{~cm}$ compr.; androceu formado por 4 estames unidos em dois pares.

5. P. cladotrichus

10. Faces adaxial e abaxial das folhas estrigosas, indumento formado por tricomas simples; pedicelo das flores masculinas variando de 1,2 a $1,5 \mathrm{~cm}$ de compr.; androceu formado por 4 a 6 estames completamente unidos 8. P. juglandifolius

8. Folhas membranáceas

11. Folhas com face adaxial glabra

12. Flores masculinas com 3 estames livres

9. P. niruri

12. Flores masculinas com 3 estames unidos 11. P. regnellianus

11. Folhas com indumento na face adaxial, mesmo que escasso

13. Indumento da face adaxial das folhas estrigoso, formado por tricomas simples; folhas com ápice agudo a cuspidado 2. P. acutifolius

13. Indumento da face adaxial das folhas variando de glabrescente a pubescente, formado por tricomas estrelado-escamiformes; folhas com ápice arredondado, obtuso ou retuso 14. Flores masculinas com 3 estames unidos 13. P. stipulatus

14. Flores masculinas com 3,5 ou 6 estames livres

15. Flores masculinas com 5 ou 6 estames; folhas com nervação cladódroma; sépalas reflexas nos frutos desenvolvidos 14. P. tenellus

15. Flores masculinas com 3 estames; folhas com nervação broquidódroma; frutos desenvolvidos sem sépalas reflexas 6. P. claussenii

1. Phyllanthus acuminatus Vahl, Symb. Bot $2: 95$. 1971.

Nomes populares: conambi, carobinha. Figura 1 A-B

Apresenta hábito arbóreo com ramos dísticos. Esta espécie também se caracteriza pela pilosidade presente na planta toda, formada por tricomas simples e alvos. Outras características que facilitam seu reconhecimento são os pedicelos das flores femininas relativamente grandes (com cerca de $11 \mathrm{~mm}$ de comprimento) as folhas com nervação broquidódroma, disco nectarífero cordiforme e as sementes com uma fenda vertical. As sépalas de ambas as flores de Phyllanthus acuminatus apresentam uma linha de néctar central que varia de vermelha a vinácea.

Espécie exclusiva das Américas, ocorrendo desde a porção norte do México até o norte da Argentina, incluindo as Antilhas (Webster 2003, Silva
\& Sales 2007). No Brasil ocorre nas regiões Norte, Centro-Oeste, Nordeste e Sudeste.

Material selecionado: BRASIL. São PAULO: Batatais, III-1994, W.M. Ferreira et al. 871 (SP); Campinas, Reserva Municipal de Santa Genebra, XI-1988, H.F. Leitão Filho \& L.P.C. Morellato 22894 (UEC); Lins, II-1941, G. Hashimoto 1309 (SP); Matão, III-1996, A. Rozza 244 (ESA, SP); Paulo de Faria, Estação Ecológica de Paulo de Faria, 1955' -1958'S e 49³1'-49³2'W, XI-2001, F. Tomasetto \& A.A. Rezende 177 (SP).

2. Phyllanthus acutifolius Poir. ex Spreng., Syst. Veg. 3:21. 1826.

Apresenta as folhas ovais, levemente discolores, com ápice agudo. As címulas são axilares e formadas sempre por flores solitárias. Phyllanthus acutifolius é muito semelhante a $P$. acuminatus, porém a primeira 
apresenta o ápice das folhas agudo e a base profundamente arredondada, enquanto na segunda o ápice das folhas varia, em geral, de cuspidado a agudo e a base de arredondada a retusa. Além disso, enquanto $P$. acuminatus apresenta hábito arbóreo, com altura variando de 2 a 8 metros, $P$. acutifolius é uma espécie subarbustiva, com altura por volta de $50 \mathrm{~cm}$.

No Brasil é encontrada apenas na região Sudeste, em Minas Gerais (Govaerts et al. 2000), Rio de Janeiro e São Paulo, exclusivamente na Serra da Mantiqueira (Webster 2002a).

Material selecionado: BRASIL. São PaUlo: São José do Barreiro, IV-1926, F.C. Hoehne \& A. Gehrt s.n. (SP17645).

\section{Phyllanthus avicularis Müll.Arg., Linnaea 32: 32.} 1863.

Figura 1 C-D

Apresenta as sépalas reflexas nos frutos maduros e pontuações translúcidas na face adaxial das folhas, muito provavelmente formadas por glândulas. Além disso, nesse táxon, as folhas são bastante estreitas, com largura variando de 2 a $4 \mathrm{~mm}$. Outra característica importante desta espécie é o disco 6-lobado presente nas flores femininas, observado também apenas em $P$. orbiculatus, já que nas outras espécies de Phyllanthus encontradas no Estado de São Paulo as flores femininas possuem disco nectarífero inteiro. Esta espécie apresenta hábitat preferencial relativamente restrito, ocorrendo apenas em várzeas de rios, entre rochas

Espécie endêmica da região Sudeste do Brasil, encontrada apenas em Minas Gerais e São Paulo.

Material selecionado: BRASIL. São Paulo: Boa Esperança do Sul, IV-1955, M. Kuhlmann 3590 (SP); Sete Barras, X-1994, M. Sugiyama \& M. Kirizawa 1258 (SP).

4. Phyllanthus caroliniensis Walter, Flora caroliniana: 228. 1788.

Figura 1 E-F

Possui as nervuras terciárias bastante reticuladas e evidentes em ambas as faces foliares e seis sépalas. Em alguns dos indivíduos analisados, a face adaxial das folhas apresentou tricomas simples, dispostos esparsamente. Os ramos, em geral dísticos, são outro caráter que pode ser utilizado no reconhecimento da espécie. Vale ressaltar que, por conta da posição das flores na axila das folhas, é difícil distinguir brácteas de estípulas, sendo essas muito semelhantes. Espécie ruderal ocorrendo em diversos tipos de ambientes tais como borda de florestas estacionais semidecíduas.

Espécie amplamente distribuída nas Américas, estendendo-se desde o sudeste dos Estados Unidos a Argentina, incluindo as Antilhas (Silva \& Sales 2007). No Brasil, distribui-se da região Norte à região Sul do país, crescendo, de acordo com Silva \& Sales (2007) na Floresta Atlântica, em Cerrado (nas matas de galeria), na Caatinga e nas florestas montanas ("brejos de altitude").

Material selecionado: BRASIL. SÃo PAULO: Campinas, XI-1953, A.S. Grotta \& J. Bartolomeu s.n. (SP 385033); São Paulo, Reserva do Parque Estadual das Fontes do Ipiranga, 23³6'S e 46³8' W, IV-1961, G. Eiten \& L.T. Eiten 2750 (SP).

5. Phyllanthus cladotrichus Müll.Arg., Linnaea 32: 25. 1863.

Nome popular: muxita.

Figura $1 \mathrm{G}$

Esta espécie pode ser reconhecida por apresentar as folhas muito maiores $(4-12 \times 1,5-6 \mathrm{~cm})$ do que as das demais espécies do gênero ocorrentes em São Paulo, o que não é usual nas espécies de Phyllanthus. O hábito variando de arbustivo a arbóreo é outra característica do táxon. O indumento denso, ferrugíneo, presente nos ramos, aliado à forma oval a elíptica e ao tamanho das folhas, bem como ao comprimento do pedicelo das flores femininas, variando de 6 a $18 \mathrm{~mm}$, auxiliam na distinção dessa espécie. De acordo com Silva \& Sales (2007) trata-se de um táxon endêmico da Bahia, porém P. cladotrichus pode também ser encontrada na Floresta Ombrófila Densa Atlântica do Estado de São Paulo.

Material selecionado: BRASIL. SÃo PAULO: Eldorado,

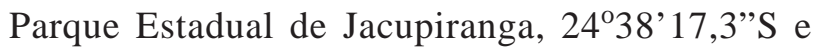
48²4'01,2”W, IX-1995, R.R. Rodrigues et al. 188 (SP); Iguape, Estação Ecológica Jureia-Itatins, VI-1992, L. Rossi et al. 1047 (SP); Peruíbe, Estação Ecológica Juréia-Itatins, VI-1994, M.R.F. Melo et al. 1096 (SP); São Paulo, Parque Municipal da Previdência, IV-1986, G. Hashimoto 1748 (SP).

6. Phyllanthus claussenii Müll.Arg., Linnaea 32: 40. 1863.

Figura $1 \mathrm{H}$

Neste táxon, a face abaxial das folhas é, em geral, verde-vinácea e a face adaxial possui tricomas 
estrelados, alvos, concentrados especialmente nas nervuras. A nervação broquidódroma, as folhas relativamente pequenas ( 9 a $15 \mathrm{~mm}$ compr.) e o pedicelo das flores femininas relativamente longo (3 a 6 mm compr.), são características que também podem ser utilizadas na distinção desta espécie quando comparada às demais espécies do gênero encontradas em São Paulo. Phyllanthus claussenii habita, em geral, campos de altitude e matas de encosta associados a afloramentos rochosos, assim como $P$. avicularis e $P$. regnellianus. Entretanto, enquanto na primeira o disco nectarífero das flores femininas é 6-lobado, nas duas outras ele é inteiro. P. claussenii é uma espécie endêmica do Brasil, ocorrendo nas regiões Nordeste, Sudeste, CentroOeste e Sul (Silva \& Sales 2007), ocorrendo apenas em matas de encosta e campos de altitude, sobre afloramentos rochosos.

Material selecionado: BRASIL. SÃo PaUlo: Altinópolis, 2124'S, 47³7'W, XI-1994, A.M.G.A. Tozzi \& L.B. Santos s.n. (SP296942); Bom Sucesso de Itararé, 2416'28"S, 4909'39”'W, XII-1997, J.M. Torezan et al. 522 (ESA); Cananéia, II-1949, G. Hashimoto 1298 (SP); Eldorado, Parque Estadual de Jacupiranga, IX-1995, V.C. Souza et al. 9064 (SP); Iguape, Estação Ecológica Juréia-Itatins, VI-1993, E.A. Anunciação \& M.Z. Gomes 242 (SP).

7. Phyllanthus glaziovii Müll.Arg., Fl. bras. 11(2): 41, t.8. 1873.

Figura 1 I

Caracteriza-se pelo ápice das folhas, em geral, longamente acuminado, pelas nervuras terciárias evidentes e densamente reticuladas e pelas folhas, na maioria, verde-acinzentadas, com margem revoluta. Os pedicelos de ambas as flores são relativamente longos quando comparados ao das demais espécies de Phyllanthus ocorrentes no Estado de São Paulo, sendo, geralmente, três vezes maiores do que as flores. $\mathrm{O}$ ovário fica quase imerso no disco nectarífero das flores femininas, que é bastante desenvolvido. Trata-se de uma espécie semelhante, vegetativamente, a P. cladotrichus da qual pode ser distinguida por apresentar ramos e pecíolos completamente glabros, ao passo que naquela os ramos apresentam indumento ferrugíneo que pode ou não estar presente também nos pecíolos.

No Brasil, Phyllanthus glaziovii ocorre desde o Paraná até o Rio de Janeiro, São Paulo e sudeste de
Minas Gerais (Webster 2002a).

Material selecionado: BRASIL. São Paulo: Pindamonhangaba, IX-2005, F.A.R.D.P. Arzolla \& J.D. Braz 1003 (SP); Santo André, Paranapiacaba, VIII-1990, A.F.Fierro 1621 (SP, SPF).

8. Phyllanthus juglandifolius Willd., Enum. Pl. Suppl.: 64. 1814.

Nomes populares: cajazeira-braba, carobinha (Silva \& Sales 2007).

Figura $1 \mathrm{~J}$

Folhas variando de 5,1 a 13,2 cm de comprimento, com textura coriácea e indumento em ambas as faces, constituído por tricomas simples, esparsamente distribuídos, concentrados especialmente nas nervuras. Apesar de em Phyllanthus cladotrichus as folhas também serem relativamente grandes, quando comparadas às das demais espécies do gênero ocorrentes no Estado de São Paulo, variando de 4 a $12 \mathrm{~cm}$ de comprimento, nesta espécie as folhas apresentam a face adaxial estrigosa com tricomas simples, face abaxial estrigosa com tricomas simples, a nervação é broquidódroma e a base é assimétrica. Todos os materiais analisados desta espécie apresentavam-se ou em estádio vegetativo ou apenas com frutos, deste modo, todas as características florais apresentadas na chave de identificação foram compiladas de Silva \& Sales (2007).

Espécie com distribuição na América do Sul e América Central (Antilhas). No Brasil, ocorrem nas regiões Norte (PA, RO), Nordeste (BA, MA, PB, PE) e Sudeste (MG, RJ, SP) (Silva \& Sales 2007).

Material selecionado: BRASIL. São Paulo: Moji das Cruzes, III-1993, S.A. Nicolau \& J.R.M. Deus 597 (SP); São Sebastião, Fazenda Jaraguá, VI-1956, M. Kuhlmann 3860 (SP).

9. Phyllanthus niruri L., Sp. Pl. 2: 981. 1753.

Nomes populares: quebra-pedra, erva-pombinha (Silva $\&$ Sales 2007).

Figura 2 A-B

Nesta espécie as folhas apresentam a base, em geral, cordada e o ápice, muitas vezes, com um apículo e são glabras em ambas as faces e levemente discolores. É, em estado vegetativo, muito semelhante a Phyllanthus tenellus, da qual difere, principalmente, pelo número de estames (5 ou $6 \mathrm{em}$ P. tenellus versus 3 em $P$. niruri). O disco nectarífero das flores masculinas é bastante desenvolvido, plano e apresenta 


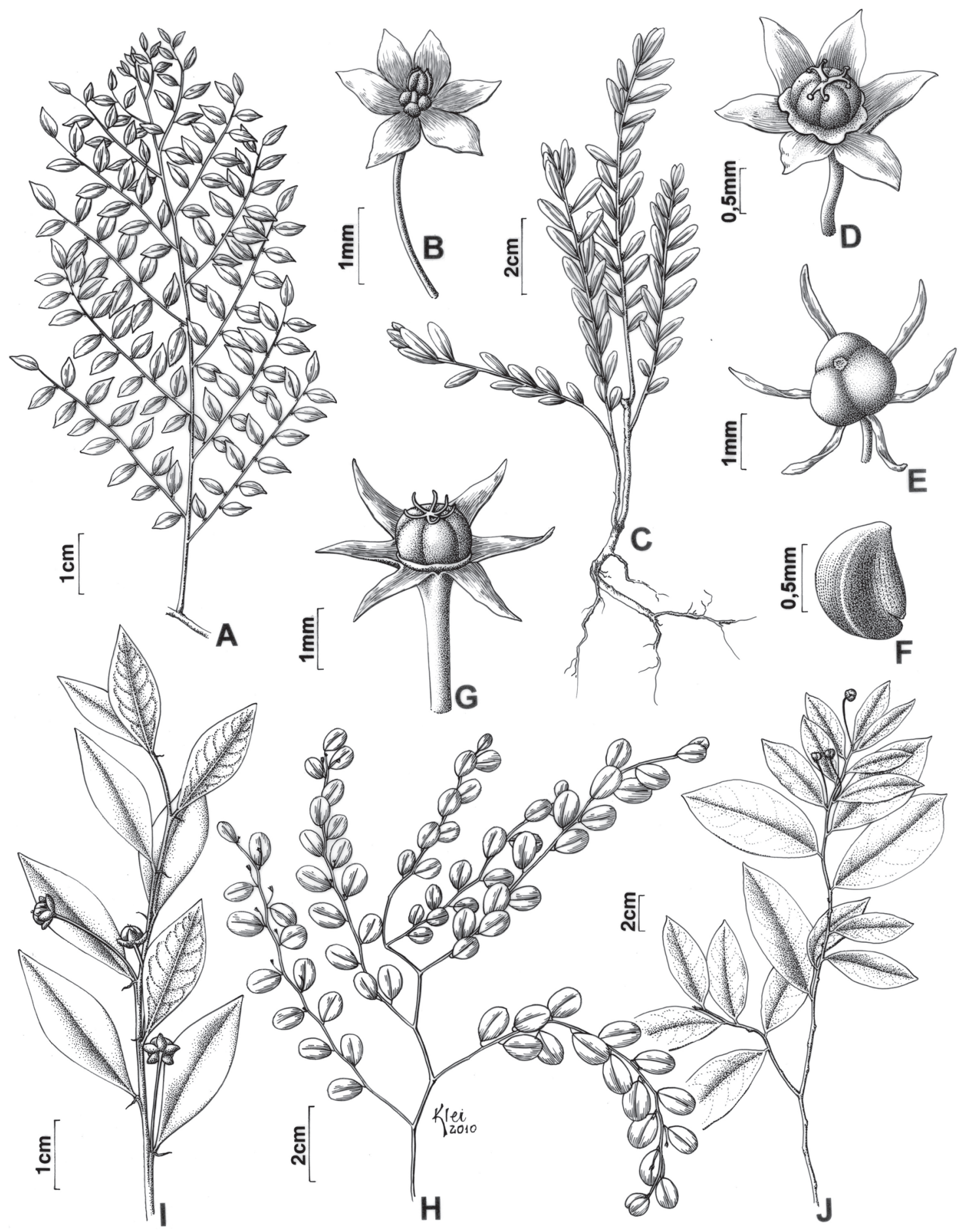

Figura 1. A-B. Phyllanthus acuminatus. A. Ramo. B. Flor masculina. C-D. Phyllanthus avicularis. C. Hábito. D. Flor feminina. E-F. Phyllanthus caroliniensis. E. Fruto. F. Semente. G. Phyllanthus cladotrichus, flor feminina. H. Phyllanthus claussenii, ramo evidenciando forma das folhas. I. Phyllanthus glaziovii, ramo evidenciando forma das folhas. J. Phyllanthus juglandifolius, ramo. (A-B: F. Tamasetto 177; C: M. Sugiyama 1258; D: M. Kuhlmann 3590; E-F: A.S. Grotta SP385033; G: G. Hashimoto 1748; H: M.P. Costa 38; I: M. Kuhlmann 3195; J: M. Kuhlmann 3860).

Figure 1. A-B. Phyllanthus acuminatus. A. Branch. B. Male flower. C-D. Phyllanthus avicularis. C. Habit. D. Female flower. E-F. Phyllanthus caroliniensis. E. Fruit. F. Seed. G. Phyllanthus cladotrichus, female flower. H. Phyllanthus claussenii branch showing leaf shape. I. Phyllanthus glaziovii branch showing leaf shape. J. Phyllanthus juglandifolius branch. (A-B: F. Tamasetto 177; C: M. Sugiyama 1258; D: M. Kuhlmann 3590; E-F: A.S. Grotta SP385033; G: G. Hashimoto 1748; H: M.P. Costa 38; I: M. Kuhlmann 3195; J: M. Kuhlmann $3860)$. 
a margem serrilhada, diferentemente do observado em P. tenellus. Planta ruderal, amplamente distribuída.

Este táxon apresenta distribuição em todo o território americano, ocorrendo desde os Estados Unidos até a Argentina, incluindo as Antilhas (Webster 1970). No Brasil, distribui-se em todas as regiões (Silva \& Sales 2007).

Material selecionado: BRASIL. São Paulo: Apiaí, 24²0'07''S, 4904'38'W, XII-1997, F. Chung 108 (ESA); Biritiba Mirim, Estação Biológica de Boracéia, 233' $-23^{\circ} 39^{\prime} \mathrm{S}, 4^{\circ} 52^{\prime}-45^{\circ} 53^{\prime} \mathrm{W}, \mathrm{V}-1985$, C.B. Toledo et al. 93 (SP); Bom Sucesso de Itararé, II2004, M.B.R. Caruzo et al. 29 (SP); Bragança Paulista III-1952, P. Gonçalves \& M. Kuhlmann 3193 (SP); Brotas, $22^{\circ} 13^{\prime} \mathrm{S}, 48^{\circ} 11^{\prime} \mathrm{W}$, VII-1995, M.C.E. Amaral et al. 95/123 (SP).

10. Phyllanthus orbiculatus Rich., Actes Soc. Hist. Nat. Paris 1: 113. 1792.

Figura $2 \mathrm{C}-\mathrm{D}$

Esta espécie, como o próprio epíteto específico sugere, apresenta as folhas bastante arredondadas, com a face adaxial coberta por tricomas alvos, distribuídos, principalmente, sobre as nervuras. Tanto as flores masculinas, quanto as femininas possuem seis sépalas, característica essa observada também em $P$. acuminatus e $P$. caroliniensis. Esses três táxons podem ser distinguidos, principalmente, pela forma bastante arredondada das folhas de P. orbiculatus. Além disso, P. acuminatus possui estames completamente unidos, formando uma coluna, ao passo que em $P$. orbiculatus os estames são completamente livres. Em P. claussenii as folhas também são arredondadas, porém nesse táxon ambas as flores possuem 5 sépalas. As sépalas de ambas as flores de P. orbiculatus apresentam uma linha de néctar central que varia de vermelha a vinácea.

Apresenta distribuição sul-americana, sendo encontrada no Brasil, Bolívia, Paraguai, Colômbia, Venezuela, Guianas, Peru e Trinidad e Tobago (Silva \& Sales 2007). No Brasil, de acordo com Webster (1957), ocorre de Norte a Sudeste.

Material selecionado: BRASIL. São PAULo: Caraguatatuba, VII-1953, W. Hoehne 15012 (SP, SPF); Itararé, II-2004, M.B.R. Caruzo et al. 26 (SP); Itirapina, VI-1993, I. Cordeiro 1231 (SP); João Ramalho, 22 ${ }^{\circ} 14$ ' 48,5'S, 5048'27,4”'W, II-1996, V.C. Souza \& J.P. Souza 10838 (SP); Lins, XI-1940, G. Hashimoto 1305 (SP).
11. Phyllanthus regnellianus Müll.Arg., Fl. Bras. 11(2): 58.1873.

Figura $2 \mathrm{E}$

Neste táxon, as estípulas são bem desenvolvidas e relativamente grandes (variando de 3 a $6 \mathrm{~mm}$ de comprimento) quando comparadas com as das demais espécies de Phyllanthus ocorrentes no Estado de São Paulo, além de serem persistentes. Outra característica que auxilia no reconhecimento do táxon é o androceu em forma de coluna, formado por três estames completamente fundidos, caráter também observado em $P$. acuminatus, $P$. riedelianus, P. stipulatus e P. umbratus. Entretanto, a distinção entre esses táxons pode ser feita facilmente por meio da forma das folhas e pela presença de margem revoluta ou não nesse órgão. Ocorre, em geral, nas bordas de matas nebulares e florestas tropicais de altitude, sempre associada a afloramentos rochosos. Em São Paulo é encontrada apenas em Campos do Jordão e São Bento do Sapucaí

Esta espécie ocorre apenas nos Estados de Minas Gerais e São Paulo.

Material selecionado: BRASIL. São PAULO: São Bento do Sapucaí, APA da Pedra do Baú, III-1997, M. Kirizawa 3349 (SP).

Material adicional examinado: BRASIL. MinAs GERAIS: Poços de Caldas, X-1983, C.T. Toradeira 32119 (SP).

12. Phyllanthus riedelianus Müll.Arg., Linnaea 32:16. 1863.

Figura $2 \mathrm{~F}$

Phyllanthus riedelianus, P. acuminatus, $P$. cladotrichus e $P$. umbratus são as espécies do Estado de São Paulo que apresentam hábito arbóreo, sendo que a primeira difere das demais por apresentar folhas elípticas, com ápice variando de acuminado a longo-acuminado. Nos ramos de $P$. riedelianus há cicatrizes deixadas pelas folhas que caem à medida em que a planta se desenvolve. Os filetes são muito curtos, em geral menores que $0,5 \mathrm{~mm}$ compr. Phyllanthus riedelianus assemelha-se morfologicamente a $P$. umbratus, sendo que a primeira apresenta nervação eucamptódroma e ocorre em matas ciliares e pastos, já a segunda possui nervação cladódroma e é encontrada em Floresta Estacional Semidecídua e em sub-bosque de mata de altitude.

Esta espécie ocorre apenas nos Estados do Paraná e São Paulo. 
Material selecionado: BRASIL. São PAULO: Igaratá, IX-1950, M. Kuhlmann 2562 (SP).

Material adicional examinado: BRASIL. PARANÁ: XII-1973, G. Hatschbach 33454 (NY); XI-1915, P.K.H Dusén 17312 (NY).

13. Phyllanthus stipulatus (Raf.) G.L. Webster, Contr. Gray. Herb. 176: 53. 1955.

Figura $2 \mathrm{G}$

Espécie muito semelhante, vegetativamente, a Phyllanthus niruri e P. tenellus. Pode ser distinguida de $P$. niruri, pois apesar de apresentar o mesmo número de estames, estes são completamente fundidos formando uma coluna. Além disso, possui indumento em pelo menos parte da folhagem e folhas com base simétrica. De $P$. tenellus pode ser separada principalmente pelo número de estames $(3 \mathrm{em}$ $P$. stipulatus versus 6 em P. tenellus) e pelos estiletes bífidos apenas na região apical, ao passo que em P. tenellus a ramificação dos estiletes se inicia na base. $\mathrm{O}$ indumento das folhas, formado por tricomas estrelado-escamiformes, é outra característica que pode ser utilizada no reconhecimento de $P$. stipulatus, embora ocorra também em $P$. orbiculatus, $P$. claussenii e $P$. tenellus. A distinção entre esses táxons pode ser feita, facilmente, pela forma e margem das folhas (revoluta em P. claussenii ou não revoluta nas outras duas espécies).

Ocorre desde o Sudeste dos Estados Unidos, abrangendo as Antilhas, até o Sul do Brasil, especialmente em locais paludosos de ambientes florestais tais como várzeas de rios, brejos e restingas (Webster 1970, 2002b). No Brasil, é encontrada de Norte a Sul (Silva \& Sales 2007).

Material selecionado: BRASIL. SÃo PAULO: Bertioga, I-1950, G. Hashimoto 3167 (SP); Boa Esperança do Sul, IV-1955, M. Kuhlmann 3591 (SP); Campos do Jordão, I-1938, G. Hashimoto 1315 (SP); Castilho, X-1998, L.R.H Bicudo et al. 7 (SP); Moji Guaçu, IX-1960, J.R. Mattos \& N.F. Mattos 8226 (SP).

14. Phyllanthus tenellus Roxb., Flora Indica 2(3): 668. 1832.

Nomes populares: arrebenta-pedra, erva-pombinha, quebra-pedra, quebra-pedra-roxo (Silva \& Sales 2007). Figura 2 H-I

Nesta espécie as folhas apresentam-se bastante opacas in siccu, além de possuírem base sempre aguda, diferentemente de Phyllanthus niruri que apresenta a base das folhas cordada a assimétrica. Além disso, em P. niruri as flores masculinas possuem 3 estames, ao passo que em $P$. tenellus esse número varia de 5 a 6 . Em P. tenellus as flores femininas possuem disco nectarífero pouco desenvolvido, ao contrário de $P$. niruri. Uma característica interessante observada nos indivíduos desse táxon é a presença das sépalas reflexas nos frutos desenvolvidos. Planta ocorrendo em campos, capoeiras e como invasora de culturas.

Trata-se de uma espécie pantropical, de acordo com Webster (1956a, 1970). No Brasil ocorre da região Norte até a região Sul (Silva \& Sales 2007).

Material selecionado: BRASIL. São PAULO: Botucatu, X-1977, J.M. Oliveira 12 (SP); Campinas, III-2004, I. Cordeiro et al. 2807 (SP); Pedregulho, 2009'41''S, 47²3'14”'W, XII-2003, A.B. Junqueira et al. 129 (SP); Pindorama, Instituto Agronômico de Campinas, XI-1938, O.T. Mendes s.n. (SP43934); Parque Estadual das Fontes do Ipiranga, I-2007, D. Vinha s.n. (SP398164).

15. Phyllanthus umbratus Müll.Arg. in DC., Prodr. 15(2): 356. 1866.

Árvores ou arvoretas, 2-8 metros de altura, flores masculinas com 3 estames unidos. Folhas membranáceas com tricomas simples na face adaxial. Planta com ramos glabros; folhas com margem revoluta e nervação cladódroma. Phyllanthus acuminatus, $P$. cladotrichus e $P$. riedelianus também apresentam este tipo de hábito, porém esses táxons podem ser distinguidos principalmente pelo formato e ápice das folhas.

No Brasil é encontrada nos estados de Minas Gerais, Rio de Janeiro e São Paulo.

Material selecionado: BRASIL. São PAulo: São Paulo, Reserva da Cidade Universitária Armando de Salles Oliveira, VIII-1979, L. Rossi 40 (SP, SPF).

Material adicional examinado: BRASIL. MinAS GERAIS: Rio Preto, II-2004, A.J.F. Junior et al. 121 (SP).

16. Phyllanthus urinaria L., Sp. pl. 1: 982. 1753.

Espécie muito semelhante, vegetativamente, a $P$. stipulatus, $P$. niruri e $P$. tenellus. Apesar de $P$. urinaria e $P$. stipulatus apresentarem flores masculinas com o mesmo número de estames e estes serem completamente fundidos formando uma coluna, estas duas espécies podem ser diferenciadas pelo 


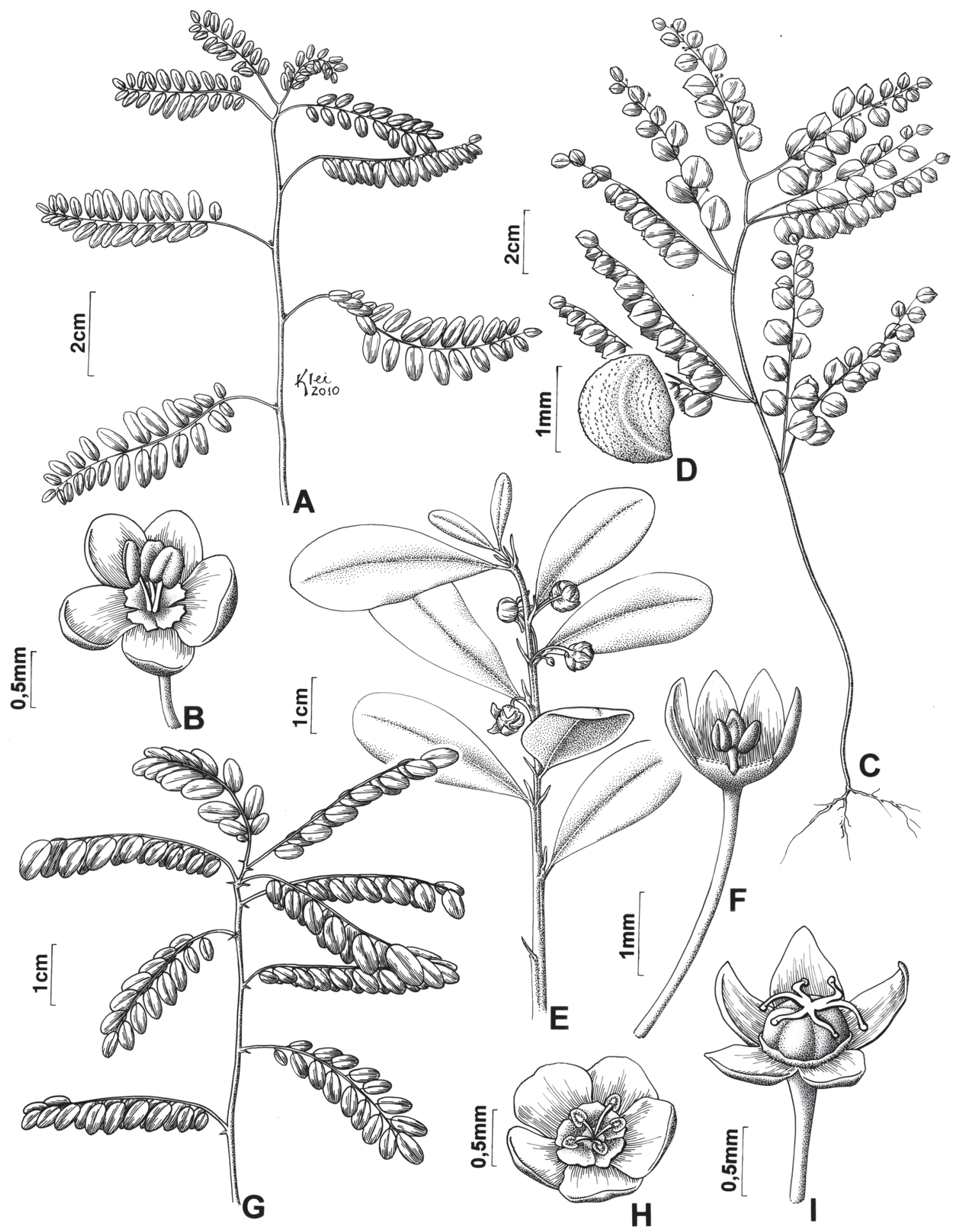

Figura 2. A-B. Phyllanthus niruri. A. Ramo. B. Flor masculina. C-D. Phyllanthus orbiculatus. C. Hábito. D. Semente. E. Phyllanthus regnellianus, ramo evidenciando forma das folhas. F. Phyllanthus riedelianus, flor masculina. G. Phyllanthus stipulatus, ramo. H-I. Phyllanthus tenellus. H. Flor masculina. I. Flor feminina. (A: G. Hashimoto 18814; B: R. Kral 75691; C: M. Sugiyama 89; D: L.R. H. Bicudo 449; E: J.Y. Tamashiro 527; F: M. Kuhlmann 2562; G: C.B. Costa; H: M.A. Pregun 1; I: O. Scavone SP385027).

Figure 2. A-B. Phyllanthus niruri. A. Branch. B. Male flower. C-D. Phyllanthus orbiculatus. C. Habit. D. Seed. E. Phyllanthus regnellianus branch showing leaf shape. F. Phyllanthus riedelianus, male flower. G. Phyllanthus stipulatus, branch. H-I. Phyllanthus tenellus. H. Male flower. I. Female flower. (A: G. Hashimoto 18814 B: R. Kral 75691; C: M. Sugiyama 89; D: L.R.H. Bicudo 449; E: J.Y. Tamashiro 527; F: M. Kuhlmann 2562; G: C.B. Costa; H: M.A. Pregun 1; I: O. Scavone SP385027). 
número de sépalas sendo 6 na primeira e 5 na segunda. $\mathrm{O}$ indumento das folhas, formado por tricomas estrelado, é uma característica que pode ser utilizada para diferenciar $P$. stipulatus, já que tal característica ocorre também apenas em $P$. orbiculatus, $P$. claussenii e $P$. tenellus. A distinção entre esses táxons pode ser feita, facilmente, pela forma das folhas e pela margem desse órgão (revoluta ou não revoluta). Diferencia-se de $P$. niruri pela união dos estames que ocorre em $P$. urinaria e não ocorre em $P$. niruri. De $P$. tenellus pode ser separada, principalmente, pelo número de estames (3 em P. urinaria versus $6 \mathrm{em}$ $P$. tenellus) e pelos estiletes bífidos a partir da metade, ao passo que em $P$. tenellus a ramificação dos estiletes se inicia na base.

Nas Américas, é referida para as Antilhas, Guianas, Guatemala, Honduras, Panamá, Venezuela e Brasil (Webster 1956b, Rossignol et al. 1987) crescendo, em geral, nas bordas de florestas litorâneas. No Brasil, ocorre de Norte a Sul, em bordas de mata e como invasora em culturas e jardins (Silva \& Sales 2007).

Material selecionado: BRASIL. São PAULO: Eldorado Paulista, III-1971, J.O. Figueiredo s.n. (SP267985).

\section{Agradecimentos}

À Fundação de Amparo à Pesquisa do Estado de São Paulo (FAPESP) pela bolsa de Iniciação Científica concedida (processo n. 2008/54838-7). Ao Instituto de Botânica da Secretaria do Meio Ambiente do Estado de São Paulo por todo apoio e estrutura para realização desse trabalho. Aos ilustradores Anna Pastorek e Klei Rodrigo Souza que realizaram as ilustrações e arte final.

\section{Literatura citada}

APG. 2003. An update of the phylogeny group classification for the orders and families of flowering plants: APG II. Botanical Journal of the Linnean Society 141: 399-436.

Chase, M.W. 1993. Phylogenetics of seed plants: an analysis of nucleotide sequences from the plastid gene rbcl. Annals of the Missouri Botanical Garden 80: 528-580.

Govaerts, R., Frodin, D.G. \& Radcliffe-Smith, A. 2000. World checklist and bibliography of Euphorbiaceae (and Pandaceae) 4. Royal Botanic Gardens, Kew, pp. 1257-1355.

Hoffmann, P., Kathriarachchi, H. \& Wurdack, K.J. 2006. A phylogenetic classification of Phyllanthaceae (Malpighiales; Euphorbiaceae s.l.). Bulletin of the Royal Botanic Gardens 61: 37-53.
Holmgren, P.K., Holmgren, N.H. \& Barnett, L.C. 1990. Index herbariorum. Part I: The herbaria of the world. New York Botanical Garden, New York.

Judd, W.S., Campbell, C.S., Kellogg, E.A. \& Stevens, P.F. 2009. Sistemática Vegetal: Um enfoque filogenético. Artmed, Porto Alegre.

Kathriarachchi, H., Hoffmann, P., Samuel, R., Wurdack, K.J. \& Chase, M.W. 2005. Molecular phylogenetics of Phyllanthaceae inferred from 5 genes (plastid atpB, matK, 3' ndhF, rbcL) and nuclear PHYC. Molecular Phylogenetics and Evolution 36: 112-134.

Kathriarachchi, H., Samuel, R., Hoffmann, P., Mlinarec, J., Wurdack, K.J., Ralimanana, H., Stuessy, T.F. \& Chase, M.W. 2006. Phylogenetics of tribe Phyllantheae (Phyllanthaceae; Euphorbiaceae sensu lato) based on nrITS and plastid matK DNA sequence data. American Journal of Botany 93: 637-655.

Radcliffe-Smith, A. 2001. Genera Euphobiacearum. Royal Botanic Gardens, Kew.

Samuel, R., Kathriarachchi, H., Hoffmann, P., Barfuss, M.H.J., Wurdack, K.J., Davis, C.C. \& Chase, M.W. 2005. Molecular phylogenetics of Phyllanthaceae: evidence from plastid matK and nuclear PHYC sequences. American Journal of Botany 92: 132-141.

Silva, M.J. \& Sales, M.F. 2007. Phyllanthus L. (Phyllanthaceae) em Pernambuco. Brasil. Acta Botanica Brasilica 21: 79-98.

Wanderley, M.G.L., Shepherd, G.J., Melhem, T.S. \& Giulietti, A.M. 2005. Flora Fanerogâmica do Estado de São Paulo, v. 5. FAPESP \& Instituto de Botânica, São Paulo.

Webster, G.L. 1956a. A monographic study of the West Indian species of the Phyllanthus L. Journal of the Arnold Arboretum 37: 91-122.

Webster, G.L. 1956b. A monographic study of the West Indian species of the Phyllanthus L. Journal of the Arnold Arboretum 37: 341-357.

Webster, G.L. 1957. A monographic study of the West Indian species of the Phyllanthus L. Journal of the Arnold Arboretum 38: 51-79.

Webster, G.L. 1970. Revision of the Phyllanthus (Euphorbiaceae) in the continental United States. Brittonia 22: 44-76.

Webster, G.L. 2002a. Three new sections and a new subgenus of Phyllanthus (Euphorbiaceae). Novon 12: 290-298.

Webster, G.L. 2002b. A synopsis of the Brazilian taxa of Phyllanthus section Phyllanthus (Euphorbiaceae). Lundelia 5: 1-26.

Webster, G.L. 2003. A synopsis of the Phyllanthus section Nothoclema (Euphorbiaceae). Lundelia 6: 9-36.

Wurdack, K.J., Hoffman, P., Samuel, R., Bruijin, A., Bank, M.V. \& Chase, M.W. 2004. Molecular phylogenetic analysis of Phyllanthaceae (Phyllanthoideae pro parte, Euphorbiaceae sensu lato) using plastid rbcL DNA sequences. American Journal of Botany 91: 1882-1900. 